\title{
Effects of Dreams on Human Stress and a Novel Server for Physics Stress
}

\author{
D.A. Adenugba \\ Department of Physics \\ The Federal University of Technology, Akure \\ P.M.B. 704, Akure, Ondo State. Nigeria.
}

\begin{abstract}
Accurate and flexible-to-use class library has been developed for Physics stress, Young modulus, strain, shear and bulk modulus and their associated parameters, using Microsoft Visual Studio, 2010. Comprehensive tests show that compressibility, volume modulus, as well as all the other functionalities work to specifications as comparisons with previous works depict. Dream is a strong causer of distress, but not in all cases. Abundance evidences depict that dreams, good and bad, simple and complex, make folks to be dismayed and confounded, wearing melancholic looks for days; however, there are exception to these. A bad dream does not always mean morose countenance. A dream destined for fulfillment enjoys uncommon favour; nothing can halt it. Effects of dreams cannot be veiled and vary widely from one person to another, causing various forms of stresses. To overcome bad dreams, meditate in God's inerrant divine word at bedtime, seek God's assistance in prayers, among others. A previous class library for rich textbox control was modified and applied to display the human stress separately and together. Software developers will find the robust Physics stress customized class library beneficial in their work. Areas of further attentions are addressed.
\end{abstract}

\section{General Terms}

Physics, Methods, Polymorphized, Rich Text Box Control, Young Modulus

\section{Keywords}

Dream, functionalities, modulus, shear, strain, stress

\section{INTRODUCTION}

Broadly speaking, there are two types of stresses---human and physics, which form the two main sections of this paper. Dream effects on human stress will be treated in the first section; the second section deals with Physics stress. Dream is a mystery and part of creation. Dream is sometimes perceived as something perplexing, awesome, unrealizable and incomprehensive as this statement depicts: "When the Lord brought back the captivity of Zion, we were like those who dream. Then our mouth was filled with laughter, and our tongue with singing. Then they said among the nations, "The Lord has done great things for them"' (Psalm 126:1). Dreams have grave effects on people. Dream troubles the Spirit and stirs the spirit to be restless, sleepless and anxious. This was said of King Nebuchadnezzar (meaning May Nebo protect the crown[1] during the second year of his reign when he dreamt: "His spirit was so troubled that his sleep left him..." "I have had a dream", Nebuchadnezzar lamented, "And my spirit is anxious to know the dream." Again, the second dream of the king frightened him and his thoughts troubled him (Daniel 4:5). Also, King Pharaoh was troubled in spirit when he dreamt (Genesis 41:8). Vision could make one to be astonished, fainted and sick for many days as it was to Daniel (Daniel 8:27). The dream of Daniel has great impact on him; his thoughts greatly troubled him and his countenance fell. "I Daniel was grieved in my spirit in the midst of my body, and the visions of my head troubled me" (Daniel 7:15). God is greater than man and He speaks in different ways, including dream, which man sometimes does not understand (Hebrews 1:1-2; Job 33:12-15).

Human mind is limited in its ability to perceive divine things. That mortal mind could not comprehend everything communicated to him, does not mean God is not speaking. Before now, God spoke through Angels, dreams and visions, Urim and Thummin, conscience, miracles, inspiration and the written word [2]. In addition, God spoke through an animal as the case of Balaam showed in Numbers 22:30-31. However, this last era, which is the Christian dispensation, God speaks through the inspired written word, the Bible only to mankind concerning Salvation. Let it be mentioned that man's Salvation is not based on dream(s), no matter how refined. It should be noted that God is still speaking mundane things through dream to people all over the globe. For more on this point, see [2].

Everybody dreams; the extent, time, frequency and place, however, vary from one person to another. Dream is not the exclusive right of the believers; unbelievers dream, too. Young and old people dream (Joel 2:28; Acts 2:17). Dreams have diverse effects on dreamers and the hearers. There are many Josephs in our societies, like Joseph the beloved son of Jacob, who dream frequently with striking results. Some folks seldom dream; but when they do, their dreams are fulfilled to the letters. We wish to discuss what dream is, causes, significant and effects of dreams; examples of dreams in the Holy Bible and how to overcome bad dreams.

Apart from showing the effects of good and bad dreams on stress, a flexible and accurate server, dvSSModCls to estimate Physics stress will be developed for tensile stress, shear, tensile strain and Young modulus and their associated parameters using Microsoft Visual Studio 2010. With regard to dream, most of the quotations are taken from the New King James Version of the Holy Bible, Thomas Nelson. Inc.

\section{WHAT IS A DREAM?}

Dreams have received extensive empirical research and concentrated scientific studies in recent time[3], leading to several definitions and facts on dream. Dream is a secret (Daniel 2:19, 27-29); the wonderful gift of nature through which diverse information, warnings and instructions are divulged. "The secret which the king (Nebuchadnezzar) has demanded" is that his dream be recounted to him, as well as its interpretation (Daniel 2:5, 6, 8, 27). The Chaldeans, the 
wise man, the astrologer, the magicians and soothsayers agreed that no mortal could disclose untold dream save the gods whose dwelling is not with the flesh (Daniel 2:10-11). Therefore, Daniel was right when he said, "But there is a God in heaven who reveals secret" (Daniel 2:28). His dwelling is not with the flesh on earth, but in heaven. "He who reveals secrets has made known to you what will be" (Daniel 2:29). Dreams are part of nature that occur during sleep; thus cannot be eliminated as long as sleep subsists and the material world exists.

Secret, as it is used in Daniel 2:28-29, is a figure of speechMetonymy which stands for dream. The secret that was revealed to Daniel was the dream of King Nebuchadnezzar(Daniel 2:30). Therefore, "This secret" means this dream. Dream is a medium of communication where the Supreme God talks to His creatures about past, current and future event(s). God spoke to people through dreams as His prophets of old received messages from Him (Numbers 12:6).Today, people still dream of different things, so God is still communicating, the level of human comprehension notwithstanding. Also, dreams, according to Henry D. Thoreau as quoted by Kendra[3], are the touchstones of our characters. Dreams, according to Activation-synthesis model of dreaming of Hobson and McClarley, are subjective interpretation of signals generated by the brain during sleep[4].

Sometimes dreams are straightforward as well as their interpretation (Genesis 37:9-10). Most often, however, they are blurred and their interpretation obscured. We have good and bad dreams; simple and complex dreams. Besides, there are true and false dreams (Jeremiah 23:32; Zechariah 10:2); visitation and experiental testing dreams [5]. Dreams come in various forms; assorted objects in diverse locations are seen in dreams. Dreams have been viewed as the language of the soul; spirit informing mind with the purpose of bringing wholeness and healing in our lives[5].

Dream is not the same thing as the gospel. Dream is not a measure of faith. The latter is procured and measured by the inerrant word of God (Romans 10:17), while the former is measured by its contents and fulfillment (Deuteronomy 13:15 ). The amount of dreams you have do not determine your salvation; Salvation is independent of dreams. Salvation is based on solid belief in Christ Jesus through obedient faith to Him. Salvation is not human reformation, according to the Church of Christ Correspondence Course on Grace (author and date not given), it is divine regeneration; it is God's operation, not human manipulation. Further this course said, Salvation is completeness in Christ; it is not competency in character!( John 3:3,5; Colossians 2:12; I Corinthians 15:10; Ephesians 3:8; see also Titus 3:3-5).

Dream is transient in nature. As soon as you wake up you may not recall the last night dream at all, not to talk of last month dream(s) or it may flicker through your mind. Dream flies away and may not be remembered, and if recalled, it may be only faintly. The ephemeral nature of a dream is likened to the shortness of the victory of the wicked and vapour-like joy of the hypocrite in the book of Job 20:1-8 (note verse 8 in particular).

\section{CAUSES AND SIGNIFICANT OF DREAMS}

Dreams sometimes are products of multitude of businesses and activities such as intensive studies. Ecclesiastes 5:3 has this to say, "For a dream comes through much activity...." Dreams, all the times, are not reliable. They may come to pass; and they may fail flatly, creating enduring distress. Thus, one should not rely on dreams, either good or bad, due to their variability and uncertainty. King Solomon statement in Ecclesiastes 5:7 corroborates this point: "For in the multitude of dreams and many words there is also vanity. But fear God." By controlling the day activities, what you see, hear and read, you may control your dreams. There are uncontrolled dreams. This situation arises when the Most High resolved to reveal something to you. God permits dreams to occur in order to reveal certain things to His people.

Dream plays a vital roles in the life of people since the inception of the world till now. The first mentioning of dream in the Holy Bible is in Genesis 20:3 when God informed and warned Abimelech, King of Gerar in his dream to return Sarah to Abraham. That dream (and dreams) occurs in over 90 places in some of the 66 books of the Holy Bible shows clearly that it is a significant part of human existence and sustainability. God reveals secret(s) unknown to mankind with or without symbol(s) at different times in the history of the world. The dream of Abimelech was lucid enough that it needs no interpreter. Some dreams, however, are encrypted that the services of interpreter will be required to unravel the mystery as in the case of King Nebuchadnezzar.

A careful study of the Holy Bible reveals that the last book of the Old Testament (O.T) does not mention the word dream or dreams. The book of Revelation, which doubled as the last book of the New Testament (N.T) and the last book of the Holy Bible, does not contain a single word of dream. Although the book of Daniel, one of the major prophets of the O.T, has at least twenty-seven places where either dream or dreams are found; none in the book of Ezekiel, also a major prophet book. Of all the twelve minor prophets of the O.T, only Joel (2:28) and Zechariah (10:2) mention dream. While the book of Daniel narrated dreams extensively, the word dream, let alone its discussion, is not found in the rich book of Proverbs, Song of Solomon and Ruth.

Dream gives direction and triggers people into action. When Gideon heard the dream a Midianite was recounting to his companion about a loaf of barley bread that tumbled into the camp of the Midian and how it struck the tent it entered, overturned and made it to collapse, alongside the interpretation, Gideon spirit was rekindled to muster Israel for war instantly. A landslide victory with just three hundred men was recorded over myriad Midianites (Judges 8:13-25). Promises are made and received in a dream; contract are tendered for, negotiated and won in a dream; and in real life only to be fulfilled to the letter. King Solomon dreamt at Gibeon and received additional things---riches, honour and long-life---- over what he requested for from God (understanding heart to discern justice) (1 Kings 3:5-15). This indicates that what one dreams about could be fulfilled precisely; promises received in a dream could be actualized in this material world in details.

Coming to the N.T, dream occurs only in two of the twentyseven books of the N.T---Matthew and Acts of the Apostles. What all these indicate is that dream is important to human 
living, and that dream does not occur in all the books of the Holy Bible. Its occurrence in some of the books of the Holy Bible shows clearly how God guided His creatures through turbulent times and revealed things in future to them. Some of these things had been thoroughly fulfilled; others on the waiting list of God Almighty for accomplishment. Dream has purpose for the present and future contrary to the suggestions of some researchers that it serves no real purpose. Dreams are regarded as internally generated meaningful signals [4]. Dreaming, according to some researchers, is essential to mental, emotional and physical well-being [3]. It is recognized as having effects on human stress. Dream, apart from pointing to future happenings (precognitive or predictive dream), shows current event(s) (clairvoyant or clear-seeing dream). The retro-cognitive dreams, according to Sharif (2013)[5], uncover hidden things of the past. Therefore, "Past, present, and future are one fluid continuum that dreams draw from." Joseph was told to accept his espoused wife, Virgin Mary in a dream (Matthew 1:20). Instructions could be received from a dream (Matthew 2:12, 19, 22). Warnings, apart from instructions, are given in a dream. Laban, the brother of Rebecca and daddy of Leah and Rachel, was sternly warned in a dream not to harm Jacob(Genesis 31:24,29). Daniel 2:30 is lucid to the fact that dream and its interpretation has a purpose. Does God just put something in us without a purpose? Everything about God's creation has purpose, which may not be transparent to mankind scientifically immediately, but the reason(s) for it is there. Dream is one of these objects which is beyond instant scientifically understanding of man. Dream, like any other thing in the world, has purpose(Ecclesiastes 3:1-8; Proverbs 16:4). With time, man will comprehend more of dreams and their usefulness in directing affairs on this earth.

Moreover, dreams are sources of warnings and instructions concerning abundance and scarcity as Pharaoh dreams in Genesis 41:1-57 depict. Dreams have been found to correlate with age, gender, culture and personal preoccupations[6]. Dreams are very revealing of what is on the mind which over time produce a very good psychological portrait of the dreamer, leading to the generation of an accurate profile of the dreamer's mind [6]. Most of us dream of current and future events. We have not heard of or read about any living soul who claims he/she has not dreamt since being on the surface of the earth. Do you know of anyone? We shall be glad to hear and know the fellow.

Dream cannot be eliminated being part and parcel of nature through which sometimes the Creator of the world reveals certain things to His creatures all over the world. Man may not comprehend dream in its entirety, its nature and purpose; however, God the Creator of all things, heavens and earth and things therein through Christ Jesus (Colossians 1:16; John $1: 3,10$ ), who have no equal, does (Isaiah 42:5; 44:24; Proverbs 3:19). “...For I am God, and there is no other; I am God, and there is none like me; declaring the end from the beginning, and from ancient times things that are not yet done..." (Isaiah 46:9-10). God reveals secrets, of which dream is a part, to the upright (Proverbs 3:32).

Occurrence of dream does not depend on colour, physique, education, religion and social status. Regardless of who you are, everybody dreams. Dream is universal. However, its frequency and reaction(s) to it may depend on some of these factors, especially on religion. The property acquired by Jacob was shown to him in a dream ever before it came to pass, indicating that dream can be actualized (Genesis 31:10-11). Dreams have the tremendous power to transform and enrich lives; assist to improve relationships, solve teething problems and diagnose illnesses[5]. In addition, Sharif (2013)[5] noted that dreams inspire creativity, fresh ideas, new inventions, teach leadership and right conduct.

\section{EFFECTS OF DREAMS}

Bad dream could cause distress; and when pleasant, joy. Dream, aside from causing terrible trouble for the dreamer, it is a potential heart pulsating raiser to the hearers of the dream. Job sums up the effects of dreams in these words: "Then you scare me with dreams and terrify me with visions, so that my soul chooses strangling and death rather than my body. I loathe my life... (Job 7:14-15). The wife of Pontius Pilate, the Governor, said, "Have nothing to do with that just Man, for I have suffered many things today in a dream because of Him" (Matthew 27:19). But, in a dream one could ride on the horse back or drive the latest Jeep being in honour. Also, one can live in an indescribable comfort instead of excruciating pains. The chief Baker and chief Butler were dismayed and confounded because of their dreams. They wore morose looks which were transparent to Joseph as he came in that morning (Genesis 40:5-6), showing that the effects of a dream, especially a bad dream, cannot be hidden. The trailing emotional feelings of a dream speak volume to the dreamer and the hearers. Also, it speaks facts about the dreamer ability to absorb shock or gruesome sights or events. Sharif (2013) [5] is right when he said feelings are more accurate and truthful than words in dreams. Therefore, feelings, to a large extent, reveal the dreamer and the hearers true identity.

When Joseph (literally means $\mathrm{He}$ will Add or increase (Genesis 30:22-24;[1]) narrated his dreams to his brothers they were troubled; his parents also were not untouched. Dream could provoke envy, jealously and hatred as the case of Joseph indicated (Genesis 37:1-11). Distress can deeply rock the hearers of a dream, causing evil thoughts to swarm their hearts. In extreme situation, dream could lead to murder, suicide, kidnapping and human trafficking. When the effects of a dream take better part of a person, strength, power and confidence are destroyed. In addition, physical and spiritual instabilities set in to cause discomfort, distress, dissatisfaction, depression, sleeplessness, obsession and illness. Why did Joseph brethren sell him to the Ishmaelites for just twenty shekels of silver (Genesis 37:28)? Was it not because of his incessant dreams, which indicated they would serve him? If they did not have ready buyer, do you not think he could have been slaughtered?

Bad dreams, no doubt, have grave evil effects on the owner and the sharers. The diverse symbols seen in a dream often frighten, creating confusion and complexity in its interpretation. Dream symbols, which may be one or combinations of archetypal, cultural and personal symbols, often have dual opposite meanings [5].

The second dream of King Nebuchadnezzar shocked Daniel to the core. He was "astonished for a time and his thoughts trouble him" when he heard the King's dream (Daniel 4:19a). Daniel was not the dreamer, yet what he heard and the interpretation of the dream petrified him. He was moved and shaken visibly that the King, the dreamer, "spoke and said to Belteshazzar (that is, Daniel), do not let the dream or its interpretation trouble you" (Daniel 4:19b). When a dream is good and delightful to the dreamer, it causes joy and brighten 
countenance. But to the hearers, it invokes open and/or secret acrimony, grudges and harms through diverse jujus and charms. It is possible, however, for the hearers to be genuinely happy about the good things heard, and this will make them cheerful. Some possible cheerful-sorrowful effects of dreams on a dreamer and the hearers are:

\section{Bad dreams often make}

(a) The dreamer to be uncheerful and even sick.

(b) The hearers may be genuinely sad concerning what he/she heard is coming to the dreamer. The attitudes of the hearers may be modified or shifted to be sympathetic toward the plight of the dreamer owing to his understanding that "He who is glad at calamity will not go unpunished"(Proverbs 17:5b).

(c) Also, the hearers may feign sadness openly, inwardly happy that the dreamer will soon be visited with calamity.

2. Bad dreams could make dreamers to be cheerful. This situation is not very common. When negative dreams mean positive things to come, the dreamer of a bad dream will be happy. There are some folks whose serious evil dreams always turn out positive for them. Dreaming about good things is then a source of sorrow to this set of people. The hearers' situations are either of 1(b) or 1(c) above.

3. Bad dreams may make a dreamer to be very joyous, realizing he/she has been informed and warned ahead of the evil to visit him/her. Thus, he applies solutions to checkmate the evil. Besides, he/she takes extra care in doing things, and/or being extraordinarily observant of events around $\mathrm{him} / \mathrm{her}$. Also, the attitudes of the hearers are similar to that in $1(\mathrm{~b})$ or 1(c) above.

4. Good dreams, unlike bad dreams, have different effects on both the dreamer and the hearers. For one, the dreamer will naturally be glad. If he becomes a millionaire in his dream with sufficient money to use to achieve his heart desires by waking up he looks cheerful. However, he should be told to pray, fast and work hard towards achieving his dream. A dream is not always actualized by tucking two hands in the pockets to climb up and claim gifts won in a dream on the top of ladder of reward. The reactions of the hearers of the dream could possibly be one of $1 \mathrm{~b}$ or $1 \mathrm{c}$ above.

\section{ANALYSIS}

Going by points 2 and 3 above, sad dreams do not always provoke distress and sad countenance. The dreamer's knowledge of his dreams dictates his reactions, feelings and countenance. Besides, his strong religious conviction and faith may stir up positive reactions to the unfavourable dream. Past experience, as a good teacher, may stoutly assist to address the bad dream situation and reactions.

A man who is swimming in affluence in his dream may turn out to be strikingly rich in real life. A person who dreams of being in hell fire is warned to reconsider his earth existence, in words and in deeds, to be in line with the word of God. In this situation, he is not doomed for eternal destruction, if he takes to warning. Therefore, a person may be destined to be rich, either a believer or an unbeliever, but no one is destined to be eternally lost in hell fire, if he believes in Christ who is the Way, the Truth and the Life (John 14:6). When a dream is billed for fulfillment all events and people will favour it; the environment and time will be conducive for its actualization.
Yet the dreamer is required to make a move, embark on a career or trade or venture through which his dream will be fulfilled.

A dream destined to be fulfilled cannot be thwarted, but the dreamer should react, put his/her talent or skill into use. The brothers of Joseph were determined to eliminate him and put an end to the actualization of his dreams. They said, "Come therefore, let us now kill him and cast him into some pit.... We shall see what will become of his dreams!" (Genesis 37:20). Reuben, the eldest son of Jacob, pleaded for him, and helpless Joseph was cast into a dry pit, waiting for his brethren final verdict. Then, traders passed by; and the thought stalked across their minds to sell him off. Joseph was sold to an Ishmaelite merchant who in turn sold him to Portiphar, an officer of Pharaoh for his dreams to be actualized. However, Joseph's gift/talent assisted him to realize his dream. If he had hidden his talent peradventure he could not have achieved his dreams. Dreams, therefore, require action on the part of the dreamer to come to fruition. It is this action that environment and people will favour.

Having a tough night dream where you engaged a Goliath in a serious fight, you woke up thoroughly wearied, what happened? You are distressed from the hard activity of the night, which indicates that you are quite active in your dream; very conscious in the dreamland, though unconscious on the earth. What happens in the dreamland can be transmitted completely to the earth and cause stress. A man woke up sweating profusely and when asked what happened he said he has been carrying heavy loads for the past two hours. That many cried out from sleep, and some yielded up the ghost in the process is not a new phenomenon. Neither is it a new news that some slept and never woke up; enjoying to stay behind in the dreamland.

Dream is a mystery that Science and Technology has not unraveled. Its several effects are fully incomprehensible; that is why your neighbour wakes up saying, "Leave me, leave me". When asked what is the matter? He recounted how someone of unknown identity was trying to hold him back in his sweet dream with a dirty hand and exposed scattered big teeth. God holds the mystery and makes it known when He wishes to some people, the interpreters, like Daniel. Indeed, there is a God in heaven who discloses secrets without whose intervention such secrets will remain mystery. Thus, folks should rely on God for the interpretation of their dreams as they seek solution through prayer and fasting; experts help also not out of place. No one who forsakes and forgets his source survives. The Yoruba adage rightly said, "Any part that forgets its source will dry up."Therefore, lean on and cling tenaciously to God, the Revealer of secrets. Anyone who thinks dreams have no meaning fails to recognize the complexity of human creation which the Psalmist summed up in Psalm 139:14 thus:"I will praise you, for I am fearfully and wonderfully made; marvellous are your works, and that my soul knows very well."

Stress obtained from a dream could have grave effect(s) on the health and life of the dreamer. Stress has no respect for gender; it has no regard for gray hair either. The day activities can cause stress, as well as activities in the night in a dream.

\section{OVERCOMING BAD DREAMS}

From various testimonies received from brethren, bad nightmares had been shown to be effectively replaced with good ones through prayers and fasting. The efficacy of 
prayers had further been shown to alter, not only the dream, but also the evil effects of the bad dreams. More so, a dreamer through extraordinary care and action(s) can avert evil effects of his dream. In addition, what we read influences our actions and behaviours, thus good materials will more than likely produce good sweet dreams.

You dream sometimes about what you think before, which resides in your subconscious mind. That is why King Solomon said that you should keep your heart with all diligence. "Keep your heart with all diligence, For out of it spring the issues of life" (Proverbs 4:23). Our real world fears and anxieties, Tenzin(2013)[7] correctly observed, follow us into our sleep. You are a product of your dream. Dream is a function of your thinking to a large extent, as well as what you are suffering from or enjoying. That is what Prophet Isaiah meant when he said, "It shall even be as when a hungry man dreams, and look --- he eats; but he awakes, and his soul is still empty; or as when a thirsty man dreams, and look --- he drinks; but he awakes, and indeed he is faint, and his soul still craves..."( Isaiah 29:8).

Since your thinking influences your life and dream, think positively. Therefore, read the Holy Bible and good books. A pure heart will dream of good things.

Another solution to overcoming bad dreams is meditation. A short passage of the Holy Bible will help you as you stay on bed, ready to sleep. Meditating and praying for guidance have been known to attain alpha dream state and help increase dream recall [5].

Moreover, run away from evil for what the eyes see penetrate into the heart to soil or purify it. That is why you have to make a covenant with your eyes not to see things that will make you stumble and have bad nightmares. Learn to say NO to any bad things during the broad daylight and in your dream you probably will do the same. The adage says, "Determination is mother of invention"; determine not to do evil and you won't do evil anywhere and anytime. Distress is in-built with evil doings and that is why God asks everyone to fear him and depart from evil, so as to be in health and renew strength (Proverbs 3:7-8). Although bad nightmares cannot be eradicated, they can be changed when we rely on God for assistance in prayers and fasting, and through reading and meditating His divine word.

\section{DREAM IN THE COMPUTER}

There are available methods to open and load Rich Text Format file [8]. Two of these methods, dvOpenLoad are further polymorphized by adding ReadOnly and WordWrap properties to prevent user from editing the Rich Text Box control (RTBC) when the content(s) is required to be viewed. WordWrap property automatically wraps words to the beginning of next line. The parts of the human stress can be viewed together and separately. There are three context menus under the Human Stress main menu which is not shown for want of space. The first two menus had been reported in previous work [8]. Upon clicking the third submenu, context menus are displaced. The short code under Abstract submenu is this:

If dvRtf.dvOpenFileLoadToRTBC(dvRTFC, dvFNam) < dcomm Then Exit Sub

Where dvRtf is the object variable declared for the modified RTF class library at client application class level. dvFNam is the file name to open, a string variable also declared at class level being required in more than five places. The structure is the same for the other submenus except the file name. The modified codes works to specification as user could not alter the RTFBC content. When the RTBC is loaded, save and print menus are enabled. They perform the operations their names suggest on the RTBC content. The diagram prepared with Insert----Shapes in MS Word did not show when the rich text format file was uploaded. This problem was resolved by rightclicking on, and copying the grouped diagram in the file to Paint Application and saved as JPEG. Without closing the Paint Application yet, the diagram was copied and pasted back in the appropriate place in the file in Word; the previous diagram deleted.

\section{PHYSICS STRESS FUNCTIONALITIES}

Engineers require the knowledge of stress and strain during designing and construction work. Young's modulus, $\mathrm{Y}$ in particular is useful to predict the elongation or compression of an object as long as the stress is less than the yield strength of the material[9-10]. Stress, $\sigma$ is a force per unit area; it has identical unit as pressure, Bulk and Young's modulus ( $\mathrm{Pa}$ or $\mathrm{N} / \mathrm{m}^{2}$ ).

$$
\sigma=\frac{\text { Force }, F}{\text { Area upon which the force acts }, A}=\frac{F}{A}
$$

When Area, A is small or narrow, $\sigma$ is very large. The fractional deformation resulting from a tensile stress is known as tensile strain $\varepsilon$, it has no unit being a ratio. Strain is the ratio of change in dimension, $\Delta L$ to the original (initial)dimension, $\mathrm{L}_{\mathrm{o}}[9-11,21]$.

$\varepsilon=\frac{\Delta L}{L_{o}}$ 


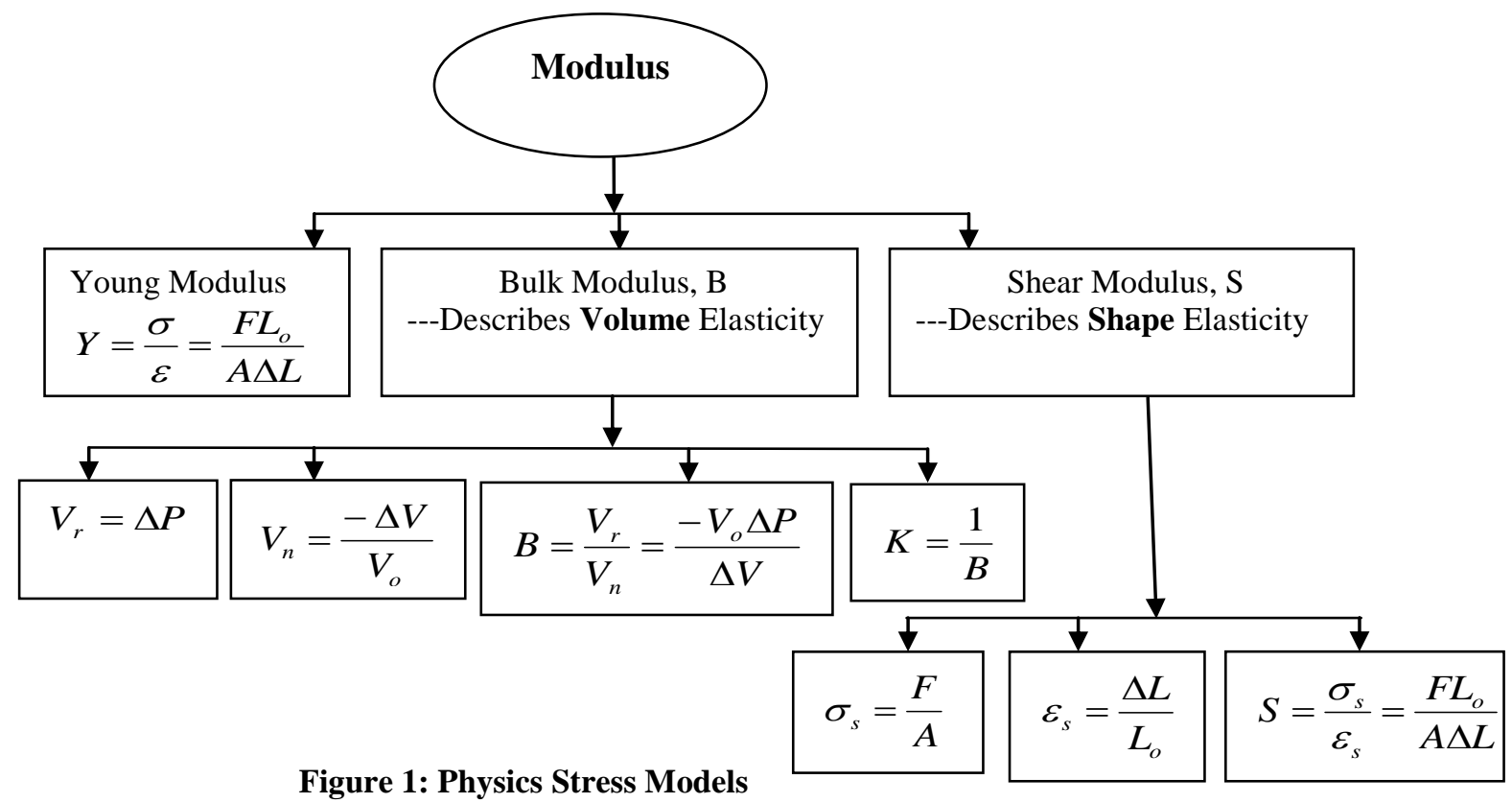

The smallest tensile stress that will produce a permanent distortion in a body is called elastic limit. Beyond this limit, upon removing stress, the body never regains its original elasticity. Young's modulus, Y or modulus of elasticity or tensile modulus, measures mechanical behaviour of materials(stiffness of an elastic material) and is given by tensile stress divided by tensile strain. Young's modulus, derived by Thomas Young(1860-65), a $19^{\text {th }}$ century British Scientist[12], is employed to predict the deflection that will occur in a statically determinate beam when a load is applied at a point in between the beam's supports[12]. Besides, the change in the dimension of a bar made of an isotropic elastic material under tensile or compressive loads can be estimated with Y. The gradient(slope) of stress-strain curve in solid mechanics at any point is known as tangent modulus. The tangent modulus of the initial, linear portion of a stress-strain curve is called Young's modulus, which is a factor of proportionality in Hooke's law under the assumption of an elastic or linear response[12]. The higher the Young's modulus, the stiffer the material [11].The reciprocal of bulk modulus, $\mathrm{B}$, is compressibility, $\mathrm{K}$. B is volume stress, $\mathrm{V}_{\mathrm{r}}$ divided by volume strain, $\mathrm{V}_{\mathrm{n}}$; it measures the object's resistance to uniform compression[10,12,13-16, 17-18]. The bulk modulus of a solid influences the speed of sound and other mechanical waves in the material, as well as the amount of energy stored in the solid in the earth's crust[19]. $\Delta \mathrm{P}$ is the change in pressure caused by the application of pressure on an object of original volume, $\mathrm{V}_{\mathrm{o}}$, which in turn causes a volume change of $\Delta \mathrm{V}$. The shear modulus is shear stress, $\sigma_{\mathrm{s}}$ divided by shear strain, $\varepsilon_{\mathrm{s}}$. For detailed derivation of the models and their well-established concepts see $[9,12-13,19-20]$. From each of the major equations in figure 1 with two operands, at least two others could be derived. Area, A in eqn. (1), for instance, could be calculated with known $\mathrm{F}$ and $\sigma$; and $\mathrm{F}$ could be obtained when the values of $\sigma$ and A are known. All derivable equations are estimated for all the major equations. For Young and Shear Moduli, there are eight derivable parameters each.

\section{PROGRAM SUMMARY AND NUMERICAL EVALUATION}

Using Microsoft Visual Studio, 2010, methods, functions and properties were written for the models in figure 1. Each model and their derivable has two types of methods: single and multiple methods. The multiple methods have reference DataGridView control(DGVC) which contains the inputs and returns the result in the last column. This last column is inserted at run time. Also, all the multiple methods have the same name as the single, and call the single method to compute the result. What the multiple methods do is to enter a loop, read the input(s) and pass it to the single method to return the computed result as argument which is stored in the last column of DGVC before the next set of data is read again until the input(s) finishes. The single methods, apart from being used internally, are available for external call being declared as public. The equation for each model can be generated dynamically. There are seven methods for generating the equations for $\mathrm{Y}, \mathrm{B}, \mathrm{Vn}, \sigma \mathrm{s}, \varepsilon \mathrm{s}, \mathrm{K}, \mathrm{S}$ in figure 1 and their related models. Each has an enumeration class that assist to specify the parameter to return its equation. For B, for instance, this is the enumeration class declared just below the server constructor.

$\begin{array}{cc}\text { Enum EnumBulkMod } & \\ d v B \_ \text {VoPcdVc } & \text { 'For } B=-(V o * P c) / V c \\ d v V c \_V o P c d B & \text { 'For } V c=-(V o * P c) / B \\ d v P c \_B V c d V o & \text { 'For } P c=-\left(B^{*} V c\right) / V o \\ d v V o \_B V c d P c & \text { 'For } V o=-\left(B^{*} V c\right) / P c\end{array}$

\section{End Enum}

When the server is instantiated and dvGetBulkModEqn method is summoned, the correct equation is retrieved for user to display where he likes. This design drastically reduces the number of methods to write and call at the client side or another server side.

The Young's modulus (Y) could be evaluated in two ways, depending on the available inputs as figure 1 depicts. The 
dvCalYoungMod single result method accepts tensile stress and tensile strain as object arguments and the output argument is a reference object for the computed Y. The second overload accepts four inputs of F, L0, A and $\Delta_{\mathrm{L}}$ and returns calculated $\mathrm{Y}$ in the last reference object argument. This polymorphized method is also adequate to effectively compute all derived models. Tables 1 and 2 show force, F and original length, L0 results respectively for multiple results for the given parameters indicated. The dvCalBulkMod method, on the other hand, accepts three inputs and the calculated B is returned in a reference argument. The compressibility, $\mathrm{K}$ method calls dvCalBulkMod method to compute B, and then finds the reciprocal of $\mathrm{B}$ which is returned as a reference object argument. The second overload simply accepts B and calculates the inverse.

All the methods were tested for all the main and derived models and found to be accurate as comparison with previous works show [20-21]. To format result on request, a Boolean write only property has to be set to true (default in the server constructor is false and the formatting string must be supplied via another property, else the Scientific default will be used.
These properties give user adequate control on their output result(s). Table 3 for shear modulus result is to nine decimal places, the setting string is "\#.000000000". Note that the results shown are extremely limited for lack of space, however, up to one hundred thousand inputs could be accepted, processed and outputted as long as the user's system has such capability. Row one text for each table can be varied, depending on what the user supply. For instance, in Table 1, we supplied Y for Young's Modulus, A for area, Lc for change in length and Lo for original dimension, while force, $\mathrm{F}$ full equation is given. SM is shear modulus in Tables 2 and 3. Needless to mention that all inputs are carefully and thoroughly checked for validity for all the model computations, and informed comment(s) provided when error occurs to show what has gone wrong. However, it is not in all cases that program is terminated when error occurs. Where there is no valid data in any input, NN is returned to indicate Not a Number and is inserted in the result column, which is the last column, as the second to the last row of Table 2 shows. All the results generated corroborate existing facts on the models treated.

Table 1: Result for force given $Y, A, L c$ and Lo

\begin{tabular}{rrrll}
\multicolumn{1}{r}{} & \multicolumn{1}{c}{$\mathbf{A}$} & \multicolumn{1}{l}{ Lc } & Lo & Force $=\left(\mathbf{Y}^{*} \mathbf{A}\right.$ \\
1.30 & 40.00 & 60.00 & 80.00 & 69.33333333 \\
0.78 & 56.80 & 44.60 & 59.50 & 59.10511211 \\
2.50 & 88.20 & 6.34 & 15.67 & 544.9897476 \\
8.23 & 100.34 & 33.00 & 40.50 & 1013.479609 \\
78.30 & 54.70 & 9.11 & 38.79 & 18236.87793
\end{tabular}

Table2: Result for original length, Lo given shear modulus(SM), A, Lc and F

\begin{tabular}{|c|c|c|c|c|c|}
\hline SM & Area, A & \multicolumn{2}{|c|}{ Change In Length, Lc } & Force, F & Original_Length, Lo \\
\hline 1.09 & 10.00 & \multicolumn{2}{|l|}{1.78} & 40.00 & 244.9438202 \\
\hline 34.78 & 80.00 & \multicolumn{2}{|l|}{0.23} & 60.00 & 725843.4783 \\
\hline 82.45 & 87.00 & \multicolumn{2}{|l|}{50.00} & 23.45 & 3364.20735 \\
\hline 1.67 & 112.50 & \multicolumn{2}{|l|}{2.30} & 100.00 & 8168.478261 \\
\hline No data & 56.00 & \multicolumn{2}{|l|}{2.50} & 27.89 & NN \\
\hline \multirow[t]{2}{*}{77.70} & 99.45 & 33.00 & & 39.12 & 9160.321418 \\
\hline & & \multicolumn{4}{|c|}{ Table 3: Result for shear modulus given $\mathrm{F}, \mathrm{Lo}, \mathrm{A}, \mathrm{L}$} \\
\hline $\mathbf{F}$ & Lo & A & Lc & \multicolumn{2}{|c|}{$\mathbf{S M}=\left(\mathbf{F}^{*} \mathbf{L o}\right) /(\mathbf{A} * \mathbf{L c})$} \\
\hline 40.00 & 1.09 & 10.00 & 1.78 & \multicolumn{2}{|c|}{2.449438202} \\
\hline 60.00 & 34.78 & 80.00 & 0.23 & \multicolumn{2}{|c|}{113.4130435} \\
\hline 23.45 & 82.45 & 87.00 & 50.00 & \multicolumn{2}{|c|}{0.444471839} \\
\hline 100.00 & 1.67 & 112.50 & 2.30 & \multicolumn{2}{|c|}{0.645410628} \\
\hline 39.12 & 77.70 & 99.45 & 33.00 & \multicolumn{2}{|c|}{0.926192239} \\
\hline
\end{tabular}

\section{CONCLUSION}

Dream is one of the media through which Almighty God communicates with human beings deep things concerning the past, present and future on earth. Dream is a medium of divine revelation that had existed since the inception of the earth.
Dreaming about good things is a source of sorrow to some people; but to some, a source of bliss and cheerfulness. Bad dreams have been found to give room for good ones through prayer and fasting. However, dream cannot be eliminated by prayers and fasting or any other methods, since it is part of 
creation to fulfill certain purposes... mundane and divine. If you do not dream this month, the following ones you will do. No rational being prays that he will not dream; and none prays for bad dream either, except those few folks whose bad dreams meant good things to come.

Effects, feelings and reactions to dreams vary greatly. They may be influenced, among other things, by knowledge, past experience and religious faith. Eustress (normal stress) may result from bad dreams when bad nightmares means the opposite to the dreamer. A dream destined to be fulfilled cannot be stopped! Parts and all the human stress can be displayed dynamically in a rich textbox control using a modified class library for rich textbox control. Using Microsoft Visual Studio, 2010, a rich and accurate class library for stress, strain, shear and their associated parameters was developed. The functionalities in the class library are tested and found to be accurate and flexible to use. A full-fledged software application with additional models and methods should be developed for the use of the scientific community.

\section{REFERENCES}

[1] William Smith. Smith's Bible Dictionary. 2002. Hendrickson Publishers. Pp.321, 437.

[2] Roger Dickson. Dickson Biblical Research Library. 2007. Volume 1. Africa International Mission, Pp.9-63.

[3] Kendra Cherry. Why Do We Dream? -Top Dream Theories. http://psychology.about.com/od/statesof consciousness/p/dream-theories.htm. (visited June, 2013).

[4] Hobson, J.A. Sleep. 1995. New York: Scientific American Library.

[5] Sharif Khan. Dream work: Tips to help you recall and interpret your dreams. 2013. www.articlesbase .com/education-articles/Dreamwork-tips-to-help- yourecall-and-interpret-your-dreams-451363.html. (visited June, 2013).

[6] William G. Domhoff. The "Purpose" of Dreams. http://ebooksforlife.com/dreams. (visited June, 2013).
[7] Tenzin Pemo. Lucid Dreaming: How to have a luciddream.www.articlesbase.com/religionarticles/lucid-dreaming-how-to-have-a-lucid- dream249944.html (visited June, 2013).

[8] Adenugba, D.A. Optimizing Stress with a Microsoft Visual Basic .Net Control. 2012. IJAIS. 4(2), 17-25.

[9] Frederick. J Bueche and Eugene Hecht. Theory And Problems of College Physics Schaum's Outline Series. 2006. McGraw-Hill., $10^{\text {th }}$ ed. Pp. 145-152.

[10] http://www.engineeringtoolbox.com/bulk- moduluselasticity-d_585.html (visited July, 2013).

[11] http://www.ehow.com/facts_7196880_bulk- modulus_ .html (visited July, 2013).

[12] http://en.wikipedia.org/wiki. (visited May, 2013).

[13] http://scienceworld.wolfram.com/physics/(visited July, 2013).

[14] http://www.ask.com/question/bulk-modulus (visited July, 2013).

[15] http://www.britannica.com/EBchecked/topic/84278/ bulk-modulus (visited July, 2013).

[16]http://projects.ivec.org/gulp/help/gulp_30_manual/gulpno de19.html (visited July, 2013).

[17] http://www.Reference.com/browse/bulk+modulus (visited July, 2013).

[18] http://human.freescience.org/htmx/bulk_modulus.php (visited July, 2013).

[19]

http://hyperphysics.phy-astr.gsu.edu /hbase/permot3.html (visited July, 2013).

[20] http://tap.iop.org/mechanics/materials/228/page46520.html(visited May, 2013).

[21] http://easycalculation.com/physics/fluid- mechanics /bulk-modulus.php(visited May, 2013). 